\title{
The work of the American emergency physician
}

\author{
Jonathan P Wyatt, Jim E Weber, Carl Chudnofsky
}

\begin{abstract}
The organisation of the American emergency health care system has changed rapidly during recent years, but it remains very different to the system in the United Kingdom. American emergency departments are organised around an attending physician based service, rather than a consultant led service. As a result, the work of the American emergency physician differs considerably from that of the United Kingdom A\&E consultant. The problems associated with working in an attending physician based service include antisocial hours of work, sleep deprivation, decreased job satisfaction, and "burn out," all in the context of a relatively hostile medicolegal climate. Although there appear to be no easy answers to some of these problems, the $A \& E$ specialist should be aware of the potential future difficulties for $A \& E$ medicine as it develops within the United Kingdom. (F Accid Emerg Med 1998;15:170-174)
\end{abstract}

Keywords: emergency medicine; USA

During 35 years of development, emergency medicine has evolved into a massive specialty in the United States. In 1994, more than 96 million emergency department attendances were treated by an estimated 17000 practitioners. ${ }^{1}$ In some respects, accident and emergency (A\&E) medicine in the United Kingdom is at an earlier stage of development compared with emergency medicine in the USA but seems to be following a similar evolutionary process. In this article we review the current position and associated problems of practising emergency medicine in the USA, within the context of the American emergency health care system. This may allow insight into the way in which United Kingdom A\&E medicine might develop in the future and help to identify those issues which might become problems.

Medicine, University of Michigan Medical School, 1500 East Medical Center Drive, Ann Arbor, Michigan 48109, USA

J E Weber

Emergency

Department, Hurley

Medical Center, One

Hurley Plaza, Flint,

Michigan 48503, USA

C Chudnofsky

Correspondence to: Mr Wyatt.

Accepted for publication 1 December 1997 towards a "managed care"/capitation system. Managed care organisations are penetrating the American health care market at an astonishing rate: in many states, up to two thirds of the population receive health care services through managed care. ${ }^{2}$ Despite the tremendous variation between managed arrangements, all seek to control costs through the integration of financing and delivery: enrolees receive services from designated providers for a prepaid or capitated amount, thereby limiting the out of pocket expenses. All managed care organisations are businesses. As businesses, they place themselves at financial risk in order to win contracts, earn profits, and take care of patients-hence their policies are actuarially based and dollar driven. ${ }^{3}$ United Kingdom A\&E specialists will watch with interest the way in which their American counterparts are affected by and deal with recent changes in the American health care system, since from one standpoint, the United Kingdom may be seen to have a national managed health care system.

The hospital system in the USA is divided between the public and private sector. Public hospitals comprise approximately $21 \%$ of the nation's 6500 hospitals. ${ }^{4}$ Compared with private hospitals, public hospitals handle a disproportionate number of patients with society's perennial ills: intravenous drug abuse, alcoholism, domestic violence, trauma, and AIDS. ${ }^{56}$ Most of the revenues generated are from "Medicare" and "Medicaid" for direct services to patients and from local governments. ${ }^{7}$ The elderly are covered by the individually state run Medicare system, which accounts for approximately $16 \%$ of public hospital funding. ${ }^{5}$ The "working poor" are insured by the individually state funded Medicaid system, which provides $38 \%$ of public hospital funding. ${ }^{5}$ Thirty three per cent of patients who present to public hospitals are uninsured, self paying patients. ${ }^{5}$ A large proportion of these patients' fees are not reimbursed: as a result, costs to the insured "paying" patients are increased for many services in order to offset the financial losses. Therefore, supplementary funds from the "disproportionate share fund," the "medical education allowance," and local governments are available to help compensate public hospitals for providing health care to the uninsured. ${ }^{5}$ President Clinton attempted to implement a plan to provide basic comprehensive health care to all Americans in 1993. ${ }^{8}$ However, this plan failed, so that at the present time there are more than 41 million uninsured Americans. ${ }^{9}$

American emergency physicians are in a similar position to physicians in other specialties in that they are no longer well protected from the financial aspects of providing care. The emergency physician is required by American law to provide emergency care to anyone who seeks it, regardless of ability to 
pay. ${ }^{10}$ Managed care organisations are currently free to deny physician reimbursement on any emergency case that is deemed "nonurgent," without fear of legal reprisal. Therefore the emergency physician is placed under considerable pressure to document and justify all investigations and treatment provided, so that appropriate billing can be made.

The provision of prehospital emergency care is shared between the fire department based services, private ambulance companies, and volunteers. All systems usually provide appropriately trained emergency medical service personnel capable of providing basic and advanced life support. Patients are transported to the nearest available - or in the case of major trauma, the most appropriate-emergency department. ${ }^{11}$ Ambulances have radio links to the emergency department, enabling emergency physicians to direct patient care in the field. ${ }^{12}$

Emergency hospital health care is organised around a network of hospitals with emergency departments of varying sizes. ${ }^{13}$ The American emergency department fulfils a similar role (in terms of receiving, triaging, diagnosing, treating, and referring patients) to the A\&E department in the United Kingdom. Similarly, the emergency physician is also responsible for interhospital transfers and any associated short stay unit. Restrictions on resources have encouraged an overall decrease in hospital inpatient care, shifting emphasis to minor injury units (urgent care centres) and "home care" settings.

\section{Career structure}

Training in emergency medicine differs substantially from that in the United Kingdom. These differences cannot be accounted for simply in terms of the different working practices of the American emergency physician. Nevertheless, the age at which an American doctor typically becomes a fully accredited independently practising ("attending") physician is similar to the age at which a United Kingdom $\mathrm{A} \& \mathrm{E}$ consultant might expect to be appointed.

During the past five years, there has been a substantial increase in accredited emergency medicine residency programmes (from 78 to 112 programmes). ${ }^{14}$ Despite the rapid growth of training programmes in emergency medicine, there remains an overall shortage of accredited (board certified) emergency physicians. ${ }^{14}{ }^{15}$ This means that while there is fierce competition to work at the more prestigious hospitals, employment prospects in emergency medicine are generally very good. Indeed, the combination of exciting work, reasonable remuneration, fixed predictable hours, and good job prospects has resulted in emergency medicine becoming a very popular career choice.

\section{Work setting}

In contrast to the United Kingdom, where $\mathrm{A} \& \mathrm{E}$ is a consultant led specialty, the intention of most community based American emergency departments is to provide an attending physician based service. The role of typical (non-academic) American emergency physicians is therefore different, in that rather than devoting much time to supervising junior doctors and performing administrative tasks, they will spend most of their time doing shift work treating patients. Even those attending physicians in teaching hospitals who are involved in supervising junior doctors spend much of their time actually seeing and treating patients, since it is mandatory that they write a note on every patient seen by a junior doctor. Additional factors which result in more direct patient contact are: the medicolegal climate (where care rendered is held to the same standard of practice regardless of who provides it) and the fact that in order to successfully bill for treatment, the signature of the attending physician must appear on the patient's notes.

Emergency physicians in community hospitals not employed by teaching or University programmes have virtually no teaching or administrative duties: it is expected that each will treat approximately 5000 patients a year. ${ }^{16}$ As a result, a medium sized emergency department needs to employ at least a dozen full time attending physicians. Although there is variation between departments, attending physicians are likely to be responsible to the emergency department director and are employed on relatively short term contracts which are renewable annually subject to satisfactory performance. In these respects, the attending physician may be considered to be less autonomous than his United Kingdom equivalent.

The disadvantages, in terms of real or perceived status, of the majority of attending physicians are offset by having few administrative responsibilities (most do not have or need an independent office or secretary) and more particularly, by generous financial reward. The mean salary for a community based, nonacademic attending physician in emergency medicine is currently $\$ 175599$ (approximately $£ 110000)$ a year for a standard 36 to 40 hour week with four weeks holiday. ${ }^{17}$ The working week is almost entirely comprised of shifts, working continuously within the emergency department. A significant proportion of these shifts involve periods that United Kingdom $A \& E$ consultants might consider "out of hours" (that is, evenings, nights, and weekends).

\section{Academic emergency physicians}

Attending physicians trying to pursue an academic career represent only a tiny minority of emergency medicine specialists. This is reflected by the relatively small number of members in the Society for Academic Emergency Medicine, compared with the much larger membership of the American College of Emergency Physicians.

Academic emergency physicians work in a different way to their non-academic community hospital based counterparts. Academics working in a large university or teaching hospital may spend as much as $90 \%$ of their clinical time supervising junior doctors in the patient care setting. Those physicians who become 
Table 1 Assistants available to the emergency physician

\begin{tabular}{|c|c|}
\hline Assistant & Role \\
\hline Nurse & $\begin{array}{l}\text { Insertion of intravenous cannula } \\
\text { Venepuncture and arranging blood tests } \\
\text { Obtaining arterial blood gases } \\
\text { Giving drugs by intravenous and other routes } \\
\text { Applying plaster of Paris } \\
\text { Performing gastric lavage } \\
\text { Insertion of urinary catheters } \\
\text { Referring patients to other specialists }\end{array}$ \\
\hline Nurse practitioner & $\begin{array}{l}\text { Supervised treatment of minor injuries } \\
\text { Suturing } \\
\text { Prescription of certain drugs }\end{array}$ \\
\hline Physician assistant & $\begin{array}{l}\text { Independent treatment of minor injuries } \\
\text { Supervised treatment of major injuries } \\
\text { Large variety of practical procedures } \\
\text { Insertion of chest tubes } \\
\text { Prescription of certain drugs (under physician licence) } \\
\text { Arranging admission to hospital wards }\end{array}$ \\
\hline Nurse anaesthetist & $\begin{array}{l}\text { Care of the airway } \\
\text { Administration of anaesthetic drugs } \\
\text { Endotracheal intubation }\end{array}$ \\
\hline Respiratory therapist & $\begin{array}{l}\text { Management of the ventilated patient, including: } \\
\text { obtaining arterial blood gases } \\
\text { adjusting the ventilation accordingly }\end{array}$ \\
\hline
\end{tabular}

associate professors or professors may have their academic achievements recognised by the university by being awarded permanent positions ("tenure"). The number of clinical shifts that each has to work a month is reduced according to administrative, teaching, and research commitments, although there is a certain minimum requirement set by the individual institution or department chairman.

While there are intellectual and other altruistic reasons for pursuing a strict academic career, it tends to be less lucrative. The current mean salary of the university employed emergency physician is $\$ 152898$ (approximately $£ 95000) .{ }^{17}$ Although an academic career may appear at first sight to be less attractive, advantages such as protected clinical time, office space with secretarial support, research space, and outstanding employer matched pension funds more than compensate.

\section{Administrative duties}

The small proportion of emergency physicians with significant administrative commitments work fewer clinical shifts in the emergency department. These administrative commitments include organising the department (emergency department director) and organising an associated residency programme (residency director). In addition, academic emergency physicians pursuing research may be able to obtain "protected time" for this, by both assuming administrative roles and winning research grants containing money to pay for other physicians to cover some of their shifts.

\section{Continuing medical education}

In the USA, there has been a requirement for continuing medical education since 1973 . The American College of Emergency Physicians demands that emergency physicians must complete 150 hours of emergency medicine postgraduate education every three years. ${ }^{18}$ Most attending physicians are easily able to meet this requirement by attending a combination of local and regional audit meetings, lectures, and case presentations. Study leave to attend courses and conferences is encouraged in principle, but in practice may be limited by time constraints. However, the job descriptions of many emergency physicians includes significant periods of time (for example, one or two weeks a year) for continuing medical education. This particularly applies to academic emergency physicians: those actively involved in research usually have little difficulty in attending conferences to present their research.

\section{The process of patient care}

The range of patients and their presenting complaints in the USA show remarkable similarities to those in the United Kingdom. ${ }^{19} 20$ The most obvious and often quoted difference relates to the type of major trauma encountered. The availability of hand guns means that penetrating gunshot injuries are far more common in the USA. ${ }^{21}{ }^{22}$ Indeed, firearms are involved in the deaths of 36500 people every year. ${ }^{23}$ Major trauma accounts for less than $1 \%$ of emergency attendances in both countries, but the coordinating and resuscitating role of the emergency physician is similar. ${ }^{19}$ There is variation between hospitals in both countries in the extent to which specialists are involved at an early stage of all forms of resuscitation. The policy adopted usually reflects available local expertise. An obvious example is whether emergency general anaesthesia and endotracheal intubation is performed by emergency department or anaesthetic staff. ${ }^{24-26}$

It is widely believed that about half of all visits to American emergency departments are for minor, or non-acute illnesses. ${ }^{27}$ This problem is also experienced by United Kingdom A\&E departments. However, in the USA the situation is compounded by the fact that 13.5 million adult Americans of the underprivileged inner city population are homeless, uninsured, and cannot afford a personal physician ("general practitioner") ${ }^{28}$ Therefore, the emergency department continues to act as the safety net for the poor and uninsured.

The available resources in the USA are part explanation for the fact that there is a generally lower threshold for relatively expensive investigations (for example, computerised tomography for head injuries). Another reason is the different medicolegal climate (see below). This is also the driving force behind the high quality documentation and production of dictated typed emergency department case notes, which are widespread in the USA.

The emergency physician in the USA performs much the same role in assessing, investigating, treating, and referring patients as his United Kingdom equivalent. However, he is greatly assisted in performing investigations, undertaking treatments, and completing documentation by an array of assisting staff (table 1). The extended role of nurses and nurse practitioners is beginning to be realised in the United Kingdom, but the roles that many other assisting staff undertake have not yet been fully 
considered. ${ }^{29}{ }^{30}$ Such staff undergo training to enable them to perform specific tasks under the supervision of the emergency physician. This facilitates patient management by the emergency physician, enabling him to treat patients at a faster rate.

Among the wide range of assistants available, the concept of a physician assistant will be most foreign to the United Kingdom doctor. These individuals follow a background of studying a medically related subject at college with a further period of university study. When the relationship between emergency physician and personal assistant is harmonious and well established, it can result in patients being assessed and treated at a very fast and efficient rate.

\section{Observation and critical decision units} As in the United Kingdom, some American emergency departments have associated short stay wards where patient care remains the responsibility of the emergency physician. Growing interest in this aspect of emergency medicine has resulted in "observation medicine" forming a separate section in the American College of Emergency Physicians. Some short stay units admit patients with a wide variety of conditions, ranging from soft tissue infections to chest pain. The economic benefits of short term observation and care provided in this way have produced pressure to increase the number and role of short stay wards further.

\section{Medicolegal considerations}

The United Kingdom A\&E consultant, who has probably never received a written complaint against him, let alone been sued for negligence, will find the medicolegal climate in the USA bewildering. Emergency attending physicians are successfully sued approximately once every five years. Insurance against medicolegal claims currently costs thousands of dollars for each emergency physician each year.

A result of the enormous amount of litigation is that each hospital employs several full time lawyers. These lawyers have a dual role: in addition to dealing with negligence claims, they invest much of their time auditing records and educating doctors on how to avoid being sued. As the number of litigation claims against $\mathrm{A} \& \mathrm{E}$ doctors increases in the United Kingdom, the need for an equivalent system, complete with improved documentation, will undoubtedly become clear.

Malpractice claims consume an enormous amount of financial resources within the medical system, generating billions of dollars in defensive medical costs. ${ }^{31} 32$ The lively, frequent and well publicised litigation causes a certain nervousness among emergency physicians, which impinges on their attitude to work and their clinical practice. ${ }^{33}$

\section{Burn out}

Various factors combine to place huge physical and psychological stresses upon emergency attending physicians. These factors include continuous high intensity work, lack of time to spend with family and friends, the threat of impending litigation, unpredictable opportunities to take food and drink breaks, irregular sleep patterns, and sleep deprivation. ${ }^{34}{ }^{35}$ It is well recognised that one result of these pressures is to become physically and emotionally drained and to develop a low sense of self achievement-this is referred to as "burn out." ${ }^{36}$ It has previously been associated with decreased job performance as well as decreased job satisfaction and premature attrition. ${ }^{37}$ It appears that burn out was previously underestimated and that the true extent of the problem is only now becoming apparent.

As $A \& E$ develops in the United Kingdom, it is likely that the pressures on consultants will increase. These pressures will originate from a variety of sources, including those listed above. Changes in work practice associated with the introduction of shift work would have a significant impact. The problem of burn out may thus occur increasingly often. United Kingdom $\mathrm{A} \& \mathrm{E}$ doctors need to anticipate this and prepare to implement appropriate preventative measures. In particular, it appears to be important to ensure adequate time away from clinical practice, in terms of both holidays and non-clinical duties (for example, research, administration) while at work. ${ }^{38}$

\section{The future}

The rapid expansion of emergency medicine in the USA carries attendant difficulties. The aim of trying to establish a service with a basic minimum standard of care, provided entirely by residency trained ("Board certified") attending physicians is an enormous challenge. It is logistically impossible in the short term to provide 26000 trained emergency physicians required to staff all American emergency departments, especially considering the problems of burn out and career change. ${ }^{14}$

The cost of health care is a major issue in the USA. The implementation of proposals to reduce costs through "managed care" will have a significant impact upon the practice of emergency medicine. Financial pressures may play a major role in moulding the future development of emergency medicine. This will be particularly true if experiments with the current system (such as greatly extending the use of short stay wards) are shown to be effective and less expensive. Parallels may be drawn with the future of $A \& E$ in the United Kingdom.

Thanks are extended to the American College of Emergency Physicians, Dr M Allswede, Professor W Barsan, Dr J Cisek, D $S$ Dronen, Dr K. Little, Dr R Maio, and Mr M Rady.

JPW received a grant from the Ethicon Foundation Fund of the Royal College of Surgeons of Edinburgh to visit hospitals in Michigan and Ohio. JEW received funding from the William Beaumont Hospital Foundation to visit hospitals in Scotland.

1 American Hospital Association. Emerging trends in hospitals, 1995/6.

2 American College of Emergency Physicians. Managed care in emergency medicine: understanding the new economics and opportunities. Dallas: American College of Emergency Physicians, 1995.

3 Luft HS. Health maintenance organizations: dimensions of performance. New York: John Wiley and Sons, 1981.

4 American Hospital Association. Hospital statistics: the American Hospital Association profile of US hospitals. Chicago: American Hospital Association, 1995. 
5 Gage LS, Burch CC, Fagnani L. Preserving access in the era of reform: America's urban health safety net. Washington DC: National Association of Public Hospitals, 1994.

6 Sterngold J. Budget slashes close hospital: issues in Los Angeles: to trim costs or the quality of care? New York Times 1995 July 17:A9.

7 Kassirer JP. Our ailing public hospitals: cure them or close them? N Engl J Med 1995;333:1348-9.

8 Clinton WJ. Televised address to the joint session of Congress and the nation, September 23, 1993.

9 Employee Benefit Research Institute. Databook on employee benefits, 3rd ed. Washington DC: Employee Benefit Research Institute, 1996.

10 Consolidated Omnibus Budget Reconciliation Act. Th Emergency Medical Treatment and Active Labor Act, 42 USC 1395 dd (1986). Washington DC: Publication number 99-272, 9121, 1986

11 Fries GR, McCalla G, Levitt MA, Cordova R. A prospective comparison of paramedic judgement and the Trauma Triage Rule in the pre-hospital setting. Ann Emerg Med 1994;24:885-9.

12 Polsky S, Krohmer J, Maningas P, McDowell R, Benson N Pons P. Guidelines for medical direction of pre-hospital EMS: American College of Emergency Physicians. Ann Emerg Med 1993;22:742-4.

13 American College of Surgeons, Committee on Trauma. Hos pital and pre-hospital resources for optimal care of the injured patient. Chicago: American College of Surgeons, 1987.

14 Haase CE, Lewis LM, Kao B. Do estimates of emergency medicine workforce underestimate current needs? Ann Emerg Med 1996;28:666-70.

15 Binder LS. Physician workforce reform and graduate medical education reallocation: potential impact on emergency medicine. Acad Emerg Med 1994;1:90-3.

16 Schwartz GR. The emergency department: organization and staffing. In: Principles and practice of emergency medicine, 2nd ed. Philadelphia: WB Saunders, 1996.

17 Kristal SL, Thompson BM, Marx JA. Emergency medicine faculty salaries: 1995-6 salary survey. Lansing, MI: Society for Academic Emergency Medicine, 1996.

18 American College of Emergency Physicians. Continuing medical education requirements. Dallas: American College of Emergency Physicians, 1995.

19 Williams MJ. Emergency department workload-a transatlantic comparison. J Emerg Med 1991;9:411-16.

20 Brown MW. Emergency: true stories from the nation's emergency rooms. New York: Villard Publishing, 1996.

21 Committee on Trauma Research. Injury in America. Washington DC: National Academy Press, 1985.
22 Wyatt JP, Beard D, Gray A, Busuttil A, Robertson CE. Rate, causes and prevention of trauma deaths in South-eas Scotland. Injury 1996;27:337-40.

23 National Safety Council Accident Facts. Itasca, Illinois: National Safety Council, 1995.

24 Teale KFH, Selby IR, James MR. General anaesthesia in accident and emergency departments. J Accid Emerg Med 1995;12:259-61.

25 Gallagher EJ, Coffey J, Lombardi G, Saef S. Emergency procedures important to the training of emergency medicine residents: who performs them in the emergency department? Acad Emerg Med 1995;2:630-3.

26 John O, Bentley B, Debehnke DJ. Airway management practices in emergency medicine residencies. Am J Emerg practices in emergency

27 Non-urgent use of hospital emergency departments by Medicaid and Medicare beneficiaries: a program inspection for the Office of Inspector General. Washington DC Department of Health and Human Services, 1983

28 Link BG, Susser E, Stueve A, Phelan J, Moore RE, Struening E. Lifetime and five-year prevalence of homelessness in the United States. Am J Public Health 1994;84:1907-12.

29 Meek SJ, Ruffles G, Anderson J, Ohiorenoya D. Nurse practitioners in major accident and emergency departments: a national survey. J Accid Emerg Med 1995; 12:177-81.

30 Freij RM, Duffy T, Hackett D, Cunningham D, Fothergill J. Radiographic interpretation by nurse practitioners in a minor injuries unit. J Accid Emerg Med 1996;13:41-3.

31 DeLew N, Greenberg G, Kinchen K. A layman's guide to the US health care system. Health Care Financial Review 1992;14:151-69.

32 Reynolds RA, Rizzo JA, Gonzalez ML. The cost of medical professional liability. JAMA 1987;257:2776-81.

33 Charles SC, Wilbert J, Franke KJ. Sued and non-sued physicians' self-reported reactions to malpractice litigation. Am J Psychiatry 1984;141:563-5.

34 Whitehead DC, Thomas H, Slapper DR. A rational approach to shift work in emergency medicine. Ann Emerg Med 1992;21:1250-8.

35 Doan-Wiggins L, Zun L, Cooper MA, Meyers DL, Chen EH. Practice satisfaction, occupational stress and attrition of emergency physicians. Wellness Task Force, Illinois Colege of Emergency Physicians. Acad Emerg Med 1995;2. 556-63.

36 Maslach C, Jackson SE. The measurement of experienced burnout. J Occup Behav 1981;2:99-113.

37 Maslach C, Jackson SE. Patterns of burnout among a national sample of public contact workers. J Health Hum national sample of public con

38 Lloyd S, Streiner D, Shannon S. Burnout, depression, life and job satisfaction among Canadian emergency physicians. J Emerg Med 1994;12:559-65.

Forms available from Sheila Barns, Faculty of Accident and Emergency Medicine, 43-45 Lincoln's Inn Fields, London WC2A 3PN.

Tel +44 (0)171 405 7071; fax +44(0)1714050318

Abstract forms must be received by the deadline of 15 June 1998

Authors will receive notification of acceptance/rejection by 31 July 1998 